\title{
Conceptualizing community resilience to natural hazards - the emBRACE framework
}

\author{
Sylvia Kruse ${ }^{1,6}$, Thomas Abeling ${ }^{2}$, Hugh Deeming ${ }^{3}$, Maureen Fordham ${ }^{4}$, John Forrester ${ }^{5}$, Sebastian Jülich ${ }^{6}$, \\ A. Nuray Karanci ${ }^{7}$, Christian Kuhlicke ${ }^{8}$, Mark Pelling ${ }^{9}$, Lydia Pedoth ${ }^{10}$, and Stefan Schneiderbauer ${ }^{10}$ \\ ${ }^{1}$ Chair for Forest and Environmental Policy, University of Freiburg, 79106 Freiburg, Germany \\ ${ }^{2}$ Climate Impacts and Adaptation, Environment Agency, 06844 Dessau-Roßlau, Germany \\ ${ }^{3}$ HD Research, Lane Head, Bentham, UK \\ ${ }^{4}$ Department of Geography, Northumbria University, Ellison Place, Newcastle upon Tyne NE1 8ST, UK \\ ${ }^{5}$ Stockholm Environment Institute \& Environment Department, York Centre for Complex Systems Analysis, \\ University of York, YO10, UK \\ ${ }^{6}$ Swiss Federal Institute for Forest Snow and Landscape Research, 8903 Birmensdorf, Switzerland \\ ${ }^{7}$ Psychology Department, Middle East Technical University, Ankara, Turkey \\ ${ }^{8}$ Helmholtz-Centre for Environmental Research - UFZ, 04318 Leipzig, Germany \\ ${ }^{9}$ Department of Geography, King's College London, Strand, London WC2R 2LS, UK \\ ${ }^{10}$ Eurac Research, 39100 Bolzano, Italy
}

Correspondence: Sylvia Kruse (sylvia.kruse@ifp.uni-freiburg.de)

Received: 28 April 2017 - Discussion started: 4 May 2017

Revised: 31 October 2017 - Accepted: 1 November 2017 - Published: 19 December 2017

\begin{abstract}
The level of community is considered to be vital for building disaster resilience. Yet, community resilience as a scientific concept often remains vaguely defined and lacks the guiding characteristics necessary for analysing and enhancing resilience on the ground. The emBRACE framework of community resilience presented in this paper provides a heuristic analytical tool for understanding, explaining and measuring community resilience to natural hazards. It was developed in an iterative process building on existing scholarly debates, on empirical case study work in five countries and on participatory consultation with community stakeholders where the framework was applied and ground-tested in different contexts and for different hazard types. The framework conceptualizes resilience across three core domains: (i) resources and capacities, (ii) actions and (iii) learning. These three domains are conceptualized as intrinsically conjoined within a whole. Community resilience is influenced by these integral elements as well as by extra-community forces comprising disaster risk governance and thus laws, policies and responsibilities on the one hand and on the other, the general societal context, natural and human-made disturbances and system change over time. The framework is a graphically
\end{abstract}

rendered heuristic, which through application can assist in guiding the assessment of community resilience in a systematic way and identifying key drivers and barriers of resilience that affect any particular hazard-exposed community.

\section{Introduction}

Community resilience has become an important concept for characterizing and measuring the abilities of populations to anticipate, absorb, accommodate or recover from the effects of a hazardous event in a timely and efficient manner (Patel et al., 2017; Almedom, 2013; Berkes and Ross, 2013; Deeming et al., 2014; Walker and Westley, 2011). This goes beyond a purely social-ecological systems understanding of resilience (e.g. Armitage et al., 2012:9) by incorporating social subjective factors, e.g. perceptions and beliefs as well as the wider institutional environment and governance settings that shape the capacities of communities to build resilience (Ensor and Harvey, 2015; Paton, 2005; Tobin, 1999). Many conceptual and empirical studies have shown that the community level is an important scale on which to build resilience that can 
enhance both the individual/household and wider population level outcomes (Berkes et al., 1998; Cote and Nightingale, 2012; Nelson et al., 2007; Ross and Berkes, 2014).

Yet, the community remains poorly theorized with little guidance on how to measure resilience building processes and outcomes. Both terms - resilience and community - incorporate an inherent vagueness combined with a positive linguistic bias and are used with increasing frequency both on their own as well as in combination (Patel et al., 2017; Mulligan et al., 2016; Brand and Jax, 2007; Strunz, 2012; Fekete et al., 2014). Both terms raise, as Norris et al. (2008) put it, the same concerns with variations in meaning.

In resilience research we can detect a disparity whereby the focus of research has often lain at either the larger geographical scales (e.g. regions) or, as in psychological research, at the level of the individual, extending to households (Ross and Berkes, 2014; Paton, 2005). Across these scales and sites of interest, resilience is consistently understood as relational. It is an ever-emergent property of socialecological and technological systems co-produced with individuals and their imaginations. As a relational feature, resilience is both held in and produced through social interactions. Arguably, the most intense interactions that are of direct relevance to those at risk are at the local level, including the influence of non-local actors and institutions. It is in this space that the community becomes integral to resilience and a crucial level of analysis for resilience research (Cutter et al., 2008; Walker and Westley, 2011; Schneiderbauer and Ehrlich, 2006).

The idea of community comprises groups of actors (e.g. individuals, organizations, businesses) which share a common identity or interest. Communities can have a spatial expression with geographic boundaries and a common identity or shared fate (Norris et al., 2008:128). Following the approach of Mulligan et al. (2016) we propose to apply a dynamic and multi-layered understanding of community, including community as a place-based concept (e.g. inhabitants of a flooded neighbourhood), as a virtual and communicative community within a spatially extended network (e.g. members of crisis management in a region) and/or as an imagined community of individuals who may never have contact with each other but who share an identity or interest.

Considering the conceptual vagueness and variations of community and resilience, only a few approaches have tried to characterize and measure community resilience comprehensively (Cutter et al., 2014; Sherrieb et al., 2010; Mulligan et al., 2016). Thus, the aim of this paper is to further fill this gap and elaborate a coherent conceptual framework for the characterization and evaluation of community resilience to natural hazards by building both on a top-down systems understanding of resilience and on an empirical, bottom-up perspective specifically including the subjective variables and how they link to broader governance settings. The framework has been developed within the European research project emBRACE in an iterative process building on existing scholarly debates and on empirical case study research in five countries (Germany, Great Britain, Italy, Switzerland, Turkey) using participatory consultation with community stakeholders, where the framework was applied and ground-tested in different regional and cultural contexts and for different hazard types. Further the framework served as a basis for guiding the assessment of community resilience on the ground.

The paper is structured as follows: the next section provides an overview of key themes and characteristics of conceptual frameworks on community resilience and identifies gaps and open questions in the current conceptual framings in the context of natural hazards. In Sect. 3 we present the methodology for the development of the emBRACE framework of community resilience. In Sect. 4 the emBRACE framework is introduced along its central elements and characteristics and illustrated by examples from the case study research. Section 5 discusses the interlinkages between the framework elements as well as the application and operationalization of the framework and reflects on the results, methodology and further research.

\section{Conceptual tensions of community resilience in disaster research and policy}

Both the concept of community and resilience are contested and this in different fields of research and policy. This chapter therefore does not aim at providing a comprehensive overview of different strands of research (for more details see Abeling et al., 2018); the ambition is rather to present a heuristic framework for understanding, explaining and assessing community resilience to natural hazards. Therefore, we present here central strands of research that influenced the development of the emBRACE framework of community resilience.

Alexander's etymological resilience journey (2013) shows that the word looks back on a "long history of multiple, interconnected meanings in art, literature, law, science and engineering. Some of the uses invoked a positive outcome or state of being, while others invoked a negative one. In synthesis, before the 20th century, the core meaning was 'to bounce back"' (ibid., 2710). However, since Holling's influential publication (1973) on Resilience and Stability of Ecological Systems the idea of restricting resilience above all to the ability of ecosystems to bounce back to a pre-disturbance state and, by implication, assume a more or less stable environment, came under increasing pressure. Therefore, another of the tensions surrounding the concept of resilience in the context of disaster risk reduction concerns its relation to social change and transformation. A divide is emerging between those that propose resilience as an opportunity for social reform and transformation in the context of uncertainty (Bahadur and Tanner, 2014; Brown, 2014; Olsson et al., 2014; MacKinnon and Derickson, 2013; SudmeierRieux, 2014; Weichselgartner and Kelman, 2015; Kelman 
et al., 2016), and those that argue for a restriction of the term to functional resistance and stability (Smith and Stirling, 2010; Klein et al., 2003). Limiting resilience to narrow interpretations of robust infrastructure would promote local disaster risk reduction that fails to address the need for social change and learning. Frameworks of disaster resilience need to account for multiple entwined pressures, (e.g. development processes, DRR and climate change; see Kelman et al., 2015) to learn and adapt and to innovate existing risk management regimes on the community level.

At the heart of this divide is the gradual translation of resilience from its firm base ${ }^{1}$ in the natural sciences to the social sciences, which brings with it a set of inherent ontological and epistemological challenges that become particularly prominent in discussions of community resilience. Rooted in ecology, resilience through the lens of Holling $(1973,1996)$ emphasized the concept of (multiple) equilibriums of systems in the face of "disturbances". This focus on returning to or progressing towards stability domains laid the foundation for the "bouncing back" narrative that continues to shape resilience policy and discourses, particularly in the area of disaster risk management and emergency planning. When discussing resilience in the context of community, however, a range of questions arise that shed light on the difficulties of translating ideas from the natural to the social sciences. These concern, amongst others, the character of disturbances in social systems (e.g. who gets disturbed by what or by whom?), the intentionality of human action (e.g. what role for purposeful interventions?), the overarching goals of resilience (e.g. what is desirable?), challenges with system boundaries (e.g. who is part of a social system?) and the role of power (e.g. who is empowered to act, participate, transform).

Besides the differences in scope of the definition between bouncing back and societal change, there is another tension about whether resilience is a normative, an analytical or a more descriptive concept (Fekete et al., 2014; Mulligan et al., 2016). While, early on, resilience was employed as a descriptive concept in ecology that attempted to integrate different notions of stability (i.e. withstanding, recovering and persisting), its thematic expansion to the analysis of socioecological systems goes hand in hand with a strong normative orientation or even prescriptive elements of how resilience ought to be organized (Brand and Jax, 2007), which is also increasingly applied as a policy goal to promote disaster risk reduction at all scales (United Nations Office for Disaster Risk Reduction, 2015, 2007). The notion of resilience is meanwhile an integral element at the international policy level to both the Hyogo Framework for Action and the Sendai Framework for Disaster Risk Reduction (United Nations Of-

\footnotetext{
${ }^{1}$ Notwithstanding Alexander's (2013) demonstration of its diverse roots and applications, the current dominance of the resilience concept owes much of its character to its ecological science derivation (e.g. Holling, 1973).
}

fice for Disaster Risk Reduction, 2015, 2007) as well as to national and local discourses on disaster risk reduction, e.g. in the UK National Community Resilience Programme (National Acadamies, 2012) or on the level of local authorities in the UK (Jacobs and Malpas, 2017; Shaw, 2012).

However, simply transplanting a descriptive concept established in ecology to a normative idea of how societies should be governed through resilience is not necessarily a step forward since there is the risk that "the role of physical shocks" is overemphasized and the relevance of "political economic factors" undertheorized (Cote and Nightingale, 2012:478). Even if the social-ecological systems approaches take into account political or economic factors, they tend to do this with a focus on functions and structures of institutions and tend to neglect the wider "political, historical and cultural meaning." (ibid). As an implication, as Lewis and Kelman argue (2012), attempts to make communities more resilient can actually result in a contrary situation, as they put them in a less tenable situation. This arises because resilience-based governance approaches have a tendency to be neglectful of social conflicts, inequalities and power (Fainstein, 2015:160; Jerneck and Olsson, 2008; Davoudi, 2012; MacKinnon and Derickson, 2013; Olsson et al., 2014), underestimate the relevance of social institutions and political struggle (Hayward, 2013; Sjöstedt, 2015) or be unheeding of the challenges associated with the idea of community participation (Bahadur and Tanner, 2014; Bahadur et al., 2013).

In addition to underestimating the relevance of socioeconomic-political and interpretational aspects, resilience itself is shaping the way disaster risk reduction is organised and how responsibilities between public and private actors are distributed. In the UK, for example, resilience is part of a responsibilization agenda in which responsibility for disaster risk reduction is intentionally devolved from the national to the local level (Department for Environment, Food and Rural Affairs, 2011; Deeming et al., 2018a). This creates opportunities but is also contested and can provoke resistance by activists (Begg et al., 2016). Despite this increasing critical engagement with resilience, the notion is "here to stay" (Norris et al., 2008:128) for the conceivable future, not only as a theoretical concept but also as a policy tool for promoting disaster risk reduction. As such, it will have direct implications for hazard-prone communities.

Based on these arguments, we identify three gaps that characterize existing resilience frameworks and are related to conceptual challenges for a comprehensive community resilience framework. First, there seems to be insufficient consideration and reflection on the role of power, governance and political interests in resilience research. Secondly, many resilience frameworks still seem to fall short of exploring how resilience is shaped by the interaction of resources, actions and learning. Due to the conceptual influence of the Sustainable Livelihood Framework (SLF) of some approaches (Chambers and Conway, 1992; Scoones, 1998; Ashley and Carney, 1999; Baumann and Sinha, 2001), 
resilience concepts tend to be focused on resources but fail to systematically explore the interaction of resources with actions and learning and how understanding these variables might then usefully illustrate disparities in how social equity, capacity and sustainability (i.e. key considerations of the SLF approach; see Chambers and Conway, 1992) manifest. Third, an explicit description of learning and change is largely absent in the literature that characterizes community resilience. So far, resilience as a theory of social change seems to remain rather vaguely specified (Cote and Nightingale, 2012).

A resilience framework which accounts for these conceptual challenges is necessarily focused on the prospects of social reform and incorporates many "soft" elements that are notoriously difficult to measure. We thus agree with the need to operationalize resilience frameworks (Carpenter et al., 2001) but argue that existing framework measurements (e.g. Cutter et al., 2008) often fail to systematically include those challenges that we consider of critical importance for community resilience.

\section{Framework development and methods used}

Developing an interdisciplinary, multi-level and multi-hazard framework for characterizing and measuring the resilience of European communities calls for the application of a multifaceted approach that adopts interdisciplinary methodological processes. Therefore, we applied a complementary research strategy with the purpose of investigating resilience on different scales, from different perspectives and by applying different research methods as well as integrating the viewpoints of distinct actors. The research team came from different disciplinary backgrounds and it was the intention that no single disciplinary approach would dominate. Rather, a democratic process of consensus building was employed to arrive at methods and outputs acceptable to all.

A first strand of this research strategy included intensive structured literature reviews. The first sketch of the community resilience framework was informed by the early review systematizing the different disciplinary discussions on resilience into thematic areas. As the project continued, specialized literature reviews complemented this first review by focusing on different aspects of the emerging framework and considering more recent publications. Throughout the project, developments in the literature were closely monitored and literature reviews were continuously updated (Abeling et al., 2018).

A second strand involved empirical case study research in five European countries investigating community resilience related to different hazard types on different scales. The five case studies comprised multiple Alpine hazards in South Tyrol, Italy and Grisons, Switzerland; earthquakes in Turkey; river floods in central Europe; combined fluvial and pluvial floods in northern England; and heatwaves in London. A number of qualitative and quantitative methodologies were adopted in the case study research in order to develop the final community resilience framework. The outcomes of this research have been used to inform the conceptual framework at different stages of the development process and helped to illustrate how the framework can be applied and adapted to different hazard types, scales and socio-economic and political contexts (Kuhlicke et al., 2016; Doğulu et al., 2016; Ikizer et al., 2015; Ikizer, 2014; Abeling, 2015a, b; Taylor et al., 2014; Deeming et al., 2018a; Jülich, 2017, 2018).

A third strand saw three participatory workshops with stakeholders in case studies in Cumbria, England; Van, Turkey; and Saxony, Germany in order to add the perspectives of different community stakeholders on the local and regional scales to the framework development. The aim of the participatory assessment workshops was to collect, validate and assess the local appropriateness and relevance of different dimensions of community resilience and indicators to measure them. With the selection of case studies in different countries and different types of communities, we took into account that different cultures and communities conceptualize and articulate resilience differently. The workshops allowed discussion with local and regional stakeholders about how resilience can be assessed. This was both a presentation and revalidation of the first results of the case study and involved working together with the stakeholders. It was also a starting point for further development of the framework.

A fourth strand involved internal review processes with project partners as well as external experts on community resilience.

\section{The emBRACE framework for characterizing community resilience}

The emBRACE framework conceptualizes community resilience as a set of intertwined components in a three-layer framework. First, the core of community resilience comprises three interrelated domains that shape resilience within the community: resources and capacities, actions and learning (see Sect. 4.1). These three domains are intrinsically conjoined. Further, these domains are embedded in two layers of extra-community processes and structures (see Sect. 4.2): first, in disaster risk governance which refers to laws, policies and responsibilities of different actors on multiple governance levels beyond the community level. It enables and supports regional, national and international civil protection practices and disaster risk management organizations. The second layer of extra-community processes and structures is influenced by broader social, economic, political and environmental context factors, by rapid or incremental socioeconomic changes of these factors over time and by disturbance. Together, the three-layers constitute the heuristic framework of community resilience (see Fig. 1), which through application can assist in defining the key drivers and 


\section{Context - change - disturbance}

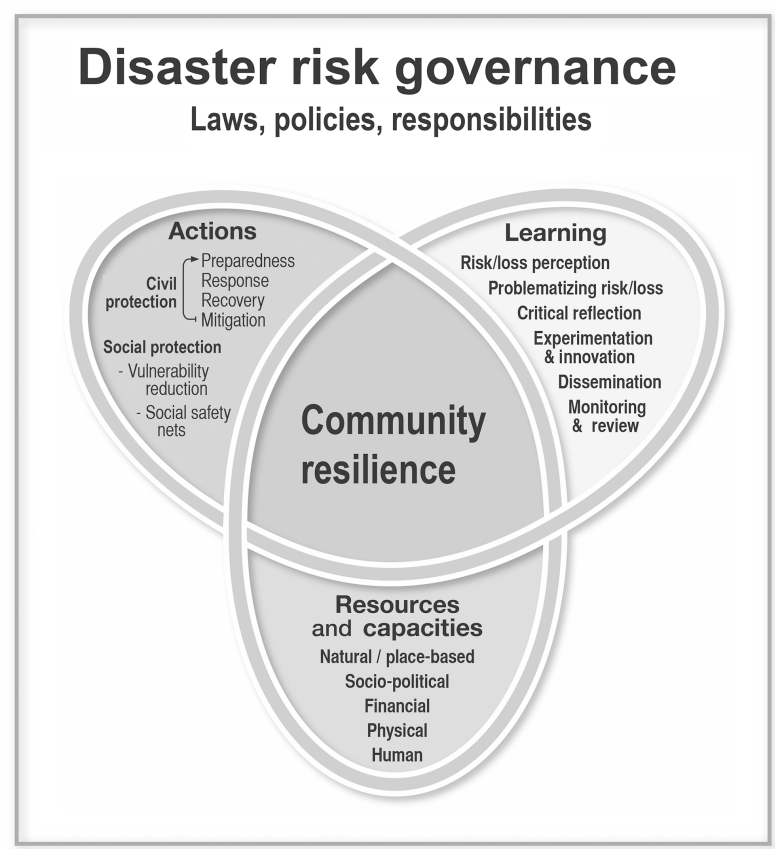

Figure 1. The emBRACE framework for community resilience to natural hazards (source: own illustration).

barriers of resilience that affect any particular community within a hazard-exposed population.

\subsection{Intra-community domains of resilience: resources and capacities, action and learning}

\subsubsection{Resources and capacities}

The capacities and resources of the community and its members constitute the first domain of the core of resilience within the community. Informed by the Sustainable Livelihoods Approach (SLA) and its iterations (Chambers and Conway, 1992; Scoones, 1998; Ashley and Carney, 1999; Baumann and Sinha, 2001) as well as the concept of adaptive capacities (Pelling, 2011), we differentiate five types of capacities and resources. This approach also addresses in parallel the need identified by Armitage et al. (2012) for material, relational and subjective variables as well as the social subjective dimension of resilience (see Sect. 1).

Natural and place-based capacities and resources relate to the protection and development of ecosystem services. This includes but is not limited to the role of land, water, forests and fisheries, both in terms of their availability for exploitation as well as more indirectly for personal well-being of community members. Place-based resources can also refer to cultural and/or heritage resources, to local public services, amenities and to the availability of access to jobs and markets.
Socio-political capacities and resources account for the importance of political, social and power dynamics and the capacity of community members to influence political decision-making. Here, institutions such as the rule of law, political participation and accountability of government actors are of critical importance. Participation in governance can be both formal, for example through elections and interest representation, and informal, for example through empowerment and resistance in political decision-making. Therefore, power dynamics in community resilience include both empowerment and resistance as well as cooperation and learning (related to the differentiation between "power to" and" power with"; see Partzsch, 2016; Allen, 1998). Therefore, structural social resources are also inherent within the structural and cognitive components of social capital (Moser and McIlwaine, 2001), i.e. networks and trust. Social capital refers to lateral relationships between family, friends and informal networks but also to more formal membership in groups, which may involve aspects of institutionalization and hierarchy. Cognitively defined trust relationships can assist in collective action and knowledge-sharing and thus seem integral for the development and maintenance of community resilience (Longstaff and Yang, 2008). Operating within the framework's disaster risk governance domain, however, it should be acknowledged that mutual social-trust relations - as might be expressed between community members - can be differentiated from trust in authority wherein hierarchical power differentials introduce an element of dependency to the relationship (Szerszynski, 1999).

Financial capacities and resources refer to monetary aspects of disaster resilience. This includes earned income, pensions, savings, credit facilities, benefits and importantly access to insurance. The role of financial capacities raises questions about availability of and access to individual and public assets and about the distribution of wealth across social collectives. The causal relationships that underpin the role of financial resources for community resources are not linear. Increases in available financial resources are not necessarily beneficial for community resilience, for example if income inequality is high and financial resources are concentrated in a very small and particular segment of society.

Physical capacities and resources for community resilience include adequate housing, roads, water and sanitation systems, effective transport, communications and other infrastructure systems. This can also refer to the availability of and the access to premises and equipment for employment and for structural hazard mitigation (i.e. both at household and community scales).

Finally, human capacities and resources focus at the individual level, integrating considerations such as gender, health and well-being, education and skills and other factors affecting subjectivities. Psychological factors are also accounted for here, including self-efficacy, belonging, previous hazard experience, coping capacities and awareness. These factors together can be understood to impact on individuals' per- 
ceptions of risk and resilience but also as enablers of the community-based leadership that drives collective action.

From the case study in Turkey, socio-political (having good governance, specific disaster legislation, supervision of the implementation of legislation, coordination and cooperation, being a civic society, having mutual trust, having moral and cultural traditional values, etc.) and human (e.g. gender, income, education, personality characteristics) resources and capacities were the most pronounced (Karanci et al., 2018).

In one of the participatory workshops an earlier version of the framework was discussed with local stakeholders regarding the case study on flooding in northern England. It revealed that for the participants, social-political and human capacities and resources were most important for characterizing their community resilience. Indicators measuring, for example, out-migration and in-migration as well as willingness to stay in the region and engage in associational activities were proposed to describe the degree of community spirit and solidarity that was considered to be crucial for their community resilience in a region that is threatened by population loss and demographic change.

\subsubsection{Actions}

Within the emBRACE framework, community resilience comprises two types of actions: civil protection and social protection. The civil protection actions refer broadly to the phases of the disaster management cycle, i.e. preparedness, response, recovery and mitigation (Alexander, 2005) which, despite longstanding academic critique (McEntire et al., 2002; Neal, 1997), are persistent in practice. Resilience actions undertaken by the community can be related to these phases (e.g. weather forecasting and warning as preparedness action). Accordingly, civil protection is focusing on hazard specific actions. We add to this social protection considerations, which include hazard independent resilience actions, e.g. measures of vulnerability reduction and building social safety nets (see Fig. 1). Social protection action includes diverse types of actions intended to provide community members with the resources necessary to improve their living standards to a point at which they are no longer dependent upon external sources of assistance (Davies et al., 2008). Social protection has been included as a main component because many resilience building actions cannot be directly attributed to civil protection action but are instead concerned with the more general pursuit of well-being and sustainability (Davies et al., 2013; Heltberg et al., 2009). For example, the presence of an active community-based voluntary and/or charity sector capable of providing social support (e.g. food banks) and funding for participatory community endeavours (e.g. a community fund) and which could be extended or expanded in times of acute, disaster-induced, community need were found to be factors that provide a certain level of security for all those affected by hazards, either directly or indirectly (Dynes, 2005).
Such social protection measures are not, however, delivered solely by the community and voluntary sector alone, so it is important to understand that these elements also relate to the much broader provision of welfare services (health, education, housing, etc.), which are ultimately the responsibility of national and local government. The inclusion of social protection as a main component of this domain therefore represents an important progression over some other frameworks, because it explicitly includes the consideration of how communities manifest resilience through their capacity to deal with and adapt to natural hazards but also their capacity to contribute equitably to reducing the wider livelihoodbased risks faced by some, if not all, of their membership.

In a case study in northern England, social support mechanisms were particularly important across multiple communities (from hill farmers to town dwellers) in the aftermath of a flood event (Deeming et al., 2018a). Key considerations were that, despite evidence of learning and adaption that had occurred between two floods in 2005 and 2009, the sheer magnitude of the latter event effectively discounted the effects of any physical mitigation and civil protection measures that had been introduced. Where non-structural measures, such as community emergency planning, had been adopted there were significant improvements in the levels and successes of response activity. However, while these actions reduced some damage (e.g. fewer vehicles flooded), where properties were inundated significant damage still resulted. Accordingly, community champions emerged who were capable of advocating community outcomes and the need for community spaces (e.g. groups or buildings) where those affected could learn by sharing experiences and deliberating plans. They proved to be key in driving the recovery as well as the concurrently occurring future mitigation efforts. Much of the support in the aftermath of the flood events was coordinated by particular officers from the statutory authorities, whose "normal" roles and skills were social rather than civil protection orientated. This emphasised the importance of understanding resilience in framework terms as a practiceencompassing process rather than as a simple measure of hazard response capability.

\subsubsection{Learning}

Learning is the third integral domain that shapes intracommunity resilience in the emBRACE framework. We attempt to provide a detailed conceptualization of learning in the context of community resilience. We follow the notion of social learning that may lead to a number of social outcomes, acquired skills and knowledge building via collective and communicative learning (Muro and Jeffrey, 2008). It occurs formally and informally, often in natural and unforced settings via conversation and mutual interest. Further, social learning is said to be most successful when the practice is spread from person to person (Reed et al., 2010) and embedded in social networks (McCarthy et al., 2011). In this 
understanding, social learning is an ongoing, adaptive process of knowledge creation that is scaled-up from individuals through social interactions fostered by critical reflection and the synthesis of a variety of knowledge types that result in changes to social structures (e.g. organizational mandates, policies, social norms) (Matyas and Pelling, 2015). Based on this understanding we conceptualise social learning as consisting of different elements from the perception of risks or losses, its problematization, to the critical reflection and testing/experimentation in order to derive new knowledge which can be disseminated throughout and beyond the community, enabling resilience at a range of societal levels (see Fig. 1). The first element, risk and loss perception, is the ability of any actor, organization or institution to have awareness of future disaster risk or to feel the impact of a current or past hazard event. Awareness can be derived from scientific or other forms of knowledge.

Second, the ability to problematize risk and loss arises once a threshold of risk tolerance has passed. A problematization of risk manifests itself as the perception of an actor that potential or actual disaster losses or the current achieved benefit-to-cost ratio of risk management are inappropriate. This includes procedural and distributional justice concerns and has the potential to generate momentum for change. Third, critical reflection on the appropriateness of technology, values and governance frames can lead to a questioning of the risk-related social contract of the community. Critical reflection is proposed as a mechanism through which to make sense of what is being learned before applying it to thinking or actions.

Fourth, experimentation and innovation refers to testing multiple approaches to solve a risk management problem in the knowledge that they will have variable individual levels of success. This can shift risk management to a new efficiency mode where experimentation is part of the short-term cost of resilience and of long-term risk reduction. In this context, innovation can be conceptualised as processes that derive an original proposition for a risk management intervention. This can include importing knowledge from other places or policy areas as well as advances based on new information and knowledge generation.

Fifth, dissemination is integral for spreading ideas, practices, tools, techniques and values that have proven to meet risk management objectives across social and policy communities. Sixth and finally, monitoring and review refers to the existence of processes and capacity that can monitor the appropriateness of existing risk management regimes in anticipation of changing social and technological, environmental, policy and hazard and risk perception contexts. The Turkish case study on earthquakes revealed that an earthquake experience in one region of the country led to learning, mostly by the state, to changes and to the adoption of new legislation and new organization for disaster management. This experience seemed to have very robust effects on attitudes towards disasters, changing the focus from disaster manage- ment to disaster risk management (Balamir, 2002). The same change process seemed to apply to individuals as well but to a smaller extent, in that an earthquake experience led to an increase in hazard awareness and preparedness (as would be predicted based on classical hazards theory; Kates, 1971).

The Italian case study in the Alpine village of Badia focuses on the perception of risks and losses as one element of resilience learning. The findings reveal that, even though people living in Badia have high risk awareness, many did not expect or prepare for an event. The interpretation of the different risk behaviour profiles shows that people who perceived themselves to be under risk of future landslide events had either personally experienced a landslide event in the past or participated in the clean-up work after the landslide event in 2012. Results from comparing the two groups of inhabitants affected by the landslide event 2012 and not affected in 2012 point in the same direction, showing that personal experience, not only recent but also past experience, together with active involvement in the response phase, lead to a higher risk perception especially when thinking about the future (Pedoth et al., 2018).

\subsection{Extra-community framing of community resilience}

\subsubsection{Disaster risk governance}

In the proposed characterization of community resilience with respect to natural hazards, the three core domains - resources and capacities, actions and learning - are embedded in two extra-community frames. The first frame is that of formal and informal disaster risk governance, which comprises laws, policies and responsibilities of disaster risk management at the local, regional, national and supra-national levels. From the case study research it became clear that community resilience and its constituent resources and capacities, action and learning processes are strongly interacting with existing formal and informal laws, policies and responsibilities of civil protection and risk management more generally (e.g. flood mapping as per the German National Water Act and the EU Flood Directive). Responsibilities relate to the actors and stakeholders involved in disaster risk management.

The wider ideas of risk governance to the specific context of a community involves focus on the interaction between communities' resources and capacities and actions as well as their learning processes. This is related to the specific framework by which responsibilities, modes of interaction and ways to participate in decision-making processes in disaster risk management are spelt out. The responsibilization agendas in the two case studies in Cumbria, England and Saxony, Germany may serve as an example. In both case studies community actions are being influenced by the downwardpressing responsibilization agenda, which is encompassed, for example, within Defra's "Making Space for Water" strategy for Great Britain and Saxony's water law in Germany, the latter of which obliges citizens to implement mitigation 
measures. This explicitly parallels Walker and Westley's call to "push power down to the local community level where sense-making, self-organization and leadership in the face of disaster were more likely to occur if local governments felt accountable for their own responses" (2011:4). The case study work showed that this not only relates to local governments (Begg et al., 2015; Kuhlicke et al., 2016) but also to the individual citizens potentially affected by natural hazards (Begg et al., 2016). More specifically, Begg et al. (2016) found that if the physical and psychological consequences are perceived as being low with regard to their most recent flood experiences, then respondents tend to accept the attribution of responsibility towards individual citizens and also report higher response efficacy (i.e. the respondents have the feeling they can reduce flood risk through their own actions) if they have taken personal mitigation measures prior to the flood event. In addition, respondents who have taken personal mitigation measures are more likely to report higher response efficacy than those who have not taken such actions and also agree with the responsibility attributed to them. In other words, if respondents took personal mitigation measures before the flood and did not experience severe consequences as a result of the flood, they are likely to agree with statements which support citizen responsibility and report high response efficacy. This shows that resilience action and learning processes are always embedded in the broader formal and informal risk governance settings.

\subsubsection{Indirect hazard-related context, social-ecological change and disturbances}

As a second extra-community framing we consider three dimensions as influential boundary conditions for community resilience: first the social, economic, political and environmental context; second, social, economic, political and environmental change over time; and third diverse types of disturbances.

The first dimension of indirect hazard-related boundary conditions for community resilience is the social, economic, political and environmental/bio-physical context. This includes contextual factors and conditions around the community itself, requiring the expansion of the analysis of community resilience to take into account the wider political and economic factors that directly or indirectly influence the resilience of the community. In different concepts and theories these contextual factors have been addressed, e.g. in institutional analysis (Whaley and Weatherhead, 2014; Ostrom, 2005), common pool resource research (Edwards and Steins, 1999) or socio-ecological systems research (Orach and Schlüter, 2016).

The analysis of contextual factors can also expand backward in time and include an analysis of change over time. Therefore, apart from the more or less stable context factors we include social, economic, political and environmental change over time as an influencing force of extra-community framing of community resilience. Disaster risk and hazard research scholars (Birkmann et al., 2010) as well as policy change scholars (Orach and Schlüter, 2016) have identified different dynamics and types of change from gradual, slow-onset change to rapid and abrupt transformation and from iterative to fundamental changes. This can include social change, economic change and policy change as well as changes in the natural environment, e.g. connected to climate change and land degradation.

Considering the third boundary condition, a broad variety of disturbances can influence the community and its resilience is partly closely interlinked with the perceived or experienced changes and the specific context factors. As already noted by Wilson (2013), disturbances can have both endogenous (i.e. from within communities, e.g. local pollution event) and exogenous causes (i.e. outside communities, e.g. hurricanes, wars) and include both sudden catastrophic disturbances (e.g. earthquakes) as well as slow-onset disturbances such as droughts or shifts in global trade (for a typology of anthropogenic and natural disturbances affecting community resilience; see Wilson, 2013). In line with Wilson we conclude that communities are never "stable" but are continuously and simultaneously affected and react to disturbances, change processes and various context factors. Therefore, disturbances can not only have severe negative impacts on a community but also trigger change and transformation that might not have activated otherwise. As a result, in empirical applications a clear-cut differentiation between contextual change over time and slow-onset disturbances or disturbances that trigger change is not always possible.

\section{Discussion and conclusion}

\subsection{Interlinkages between the domains and extra-community framing}

Considering the intertwined components of the proposed framework, research can be guided by acknowledging the complexity of the possible interactions between the resources and capacities, learning and actions domains in shaping community resilience. Therefore, efforts that evaluate these multiple levels; their interactions; and how they operate in different contexts for different hazards can provide an enriching evaluation of community resilience.

An example of how the emBRACE framework of community resilience helped to reveal the interrelatedness of sociopolitical and human resources in the civil protection actions and the importance of social solidarity and trust as important contextual factor is delivered in the case study work in the city of Van, Turkey. Here the exploration of individual resilience after a severe earthquake proved how influential the contextual factors are. The results indicated that the political context played an important role in shaping survivors' perceptions of their own resilience. Doğulu et al. (2016) shows 
that community resilience is facilitated when provision of post-quake aid and services is based on equality and trust (and not nepotism and corruption) and not hindered by discrepancy of political views among government bodies, community members and NGOs.

Further, the analysis revealed that the earthquake experience in the Marmara region of Turkey in 1999, 12 years earlier influenced the resilience of the community following the Van earthquake, based on learning processes that resulted, for example, in a change in the public disaster management by state organizations as well as the adoption of new legislation. Thus, especially for the state institutions, the impact of a past disturbance may lead to significant changes in disaster risk management, which in turn are likely to contribute to fostering community resilience in Van and beyond (Karanci et al., 2018). This example shows how the framework provides an understanding of the interrelatedness of the three domains and the importance of their interactions in shaping community resilience. Yet, the specific types of relations and interlinkages are case specific, i.e. influenced by various external variables. How to specify these and develop typologies of linkages and relations will need to be investigated in further research.

\subsection{Application and operationalization of the framework in indicator-based assessments}

The emBRACE framework for community resilience was iteratively developed and refined based on the empirical research of the specific local-level systems within the five case studies of emBRACE; thus it is strongly supported by local research findings on community resilience. It was mainly developed to characterize community resilience in a coherent and integrative way. Nonetheless, it was also developed for measuring resilience and is thus a heuristic to be operationalized in the form of an indicator-based assessment. Thus, the framework provides one possible - but empirically legitimized - structure and route with which to select and conceptually locate indicators of community resilience.

Within the emBRACE project we derived case-studyspecific community resilience indicators as well as a set of more concise, substantial indicators that are generalizable across the case studies (Becker et al., 2018). The generalizable key indicators include a wider range of indicators from more quantitative indicators, like the presence of an active third-sector emergency coordination body or the percentage of households in the community that subscribed to an earlywarning system, operationalizing the domain of civil protection action, up to more qualitative indicators such as so$\mathrm{cial} / \mathrm{mutual}$ trust and the sense of belonging to a community, applying the domain of human and social resources and capacities.

Besides identifying and selecting suitable indicators, it is crucial to understand how to develop, integrate, interpret and apply indicators (Jülich, 2018; Bahadur and Tanner, 2014).
Concrete instructions are needed to provide a useful source of information for proper indicator application in practice and we recommend using some form of guideline for community resilience indicator development (see for example Becker et al., 2015). In particular, the possible methods of data collection for the constituent parts of this framework require attention, since they affect not only the methods adopted to parameterise the indicators but also the scale of application.

\subsection{Reflections on the results and emBRACE methodology and limits of the findings}

The term "resilience" is both ubiquitous and indeterminate. Similarly, "community" is equally pervasive and prone to common sense understandings which appear to obviate critical discursive engagement. Together, the two concepts represent both a challenge and an opportunity to influence the shape of effective and inclusive disaster risk reduction. The frequently simplistic and bounded uses of "community resilience" (across a range of sectors but most particularly in the civil protection and emergency management fields) limit the reach of risk reduction endeavours through a narrow focus on technical interventions at the expense of recognizing and enabling social transformations. The proposed threelayered framework for characterizing community resilience was developed deductively by considering theoretical approaches of resilience from various disciplinary backgrounds and state-of-the-art research, and it was also developed inductively based on empirical insights from our case study work. The result is a theory-informed heuristic that has the potential to guide empirical research as well as disaster management and community development in a more inclusive and expansive way.

Research and practice rarely include all elements we have identified but often focus on some specific domains and their interaction in more detail. When guiding disaster management and community development the framework helps to highlight the importance of the multiple factors that are related to community resilience. Whether the framework is to inform scientific or more practical applications, in most cases it will be necessary to adapt the framework to the specific context in which it is applied, e.g. cultural background, hazard types or the socio-political context. This framework was developed in a European context, and while the research team has drawn upon their wider research knowledge and experience it was not tested outside that geographic boundary.

The emBRACE framework was developed as a heuristic device, i.e. a strategy based on experience and as an aid to communication and understanding, but it is not guaranteed to be optimal or perfect. The framework should be subject to further research both for further conceptualizing community resilience and applying and specifying the framework in various contexts of community resilience. 
Data availability. This article is a conceptual contribution on community resilience and delivers a synthesis of various empirical case study work. The results of the empirical work and underlying data can be found in the referenced articles and $\mathrm{PhD}$ thesis, pooled in the forthcoming book of Deeming et al. (2018b).

Competing interests. The authors declare that they have no conflict of interest.

Disclaimer. This article reflects the views of the authors only, and the European Commission cannot be held responsible for any use which may be made of the information contained therein.

Acknowledgements. This study has received funding from the European Union's Seventh Framework Programme for research, technological development and demonstration under grant agreement no. 283201. Special thanks go to Astrid Björnsen Gurung and Valentin Ruegg for their graphical support during the framework development. The article processing charge was funded by the German Research Foundation (DFG) and the Albert Ludwigs University Freiburg in the funding programme Open Access Publishing.

Edited by: Sven Fuchs

Reviewed by: Hartmut Fünfgeld, Ilan Kelman, and Christiane Stephan

\section{References}

Abeling, T.: According to plan?: Disaster risk knowledge and organizational responses to heat wave risk in London, UK, Ecosystem Health and Sustainability, 1, 1-8, https://doi.org/10.1890/EHS14-0022.1, 2015a.

Abeling, T.: Can we learn to be resilient? Institutional constraints for social learning in heatwave risk management in London, UK, Unpublished doctoral dissertation, King's College London, University of London, London, United Kingdom, 2015b.

Abeling, T., Huq, N., Chang-Seng, D., Birkmann, J., Wolfertz, J., Renaud, F., and Garschagen, M.: Understanding community disaster resilience, in: Framing Community Disaster Resilience: resources, capacities, learning and action, edited by: Deeming, H., Fordham, M., Kuhlicke, C., Pedoth, L., Schneiderbauer, S., and Shreve, C., Wiley Blackwell, Chichester, West Sussex, United Kingdom, in press, 2018.

Alexander, D.: Towards the development of a standard in emergency planning, Disaster Prev. Manag., 14, 158-175, https://doi.org/10.1108/09653560510595164, 2005.

Alexander, D. E.: Resilience and disaster risk reduction: an etymological journey, Nat. Hazards Earth Syst. Sci., 13, 2707-2716, https://doi.org/10.5194/nhess-13-2707-2013, 2013.

Allen, A.: Rethinking Power, Hypatia, 13, 21-40, https://doi.org/10.1111/j.1527-2001.1998.tb01350.x, 1998.

Almedom, A. M.: Resilience: Outcome, Process, Emergence, Narrative (OPEN) theory, On the Horizon, 21, 15-23, https://doi.org/10.1108/10748121311297030, 2013.
Armitage, D., Béné, C., Charles, A. T., Johnson, D., and Allison, E. H.: The Interplay of Well-being and Resilience in Applying a Social-Ecological Perspective, Ecol. Soc., 17, https://doi.org/10.5751/ES-04940-170415, 2012.

Ashley, C. and Carney, D.: Sustainable livelihoods: Lessons from early experience, Department for International Development, London, 1999.

Bahadur, A. and Tanner, T.: Transformational resilience thinking: Putting people, power and politics at the heart of urban climate resilience, Environ. Urban, 26, 200-214, https://doi.org/10.1177/0956247814522154, 2014.

Bahadur, A. V., Ibrahim, M., and Tanner, T.: Characterising resilience: unpacking the concept for tackling climate change and development, Clim. Dev., 5, 55-65, https://doi.org/10.1080/17565529.2012.762334, 2013.

Balamir, M.: Painful steps of progress from crisis planning to contingency planning: Changes for disaster preparedness in Turkey, J. Conting. Crisis Man., 10, 39-49, 2002.

Baumann, P. and Sinha, S.: Linking Development with Democratic Processes in India: Political Capital and Sustainable Livelihoods Analysis, Natural Resource Perspectives, 8, 2-5, 2001.

Becker, D., Schneiderbauer, S., Forrester, J., and Pedoth, L.: Guidelines for development of indicators, indicator systems and provider challenges, Deliverable 3.5 emBRACE project, available at: http://www.embrace-eu.org/outputs (last access: December 2017), 2015.

Becker, D., Schneiderbauer, S., Forrester, J., and Pedoth, L.: Combining Quantitative and Qualitative Indicators for Assessing Community Resilience to Natural Hazards, in: Framing Community Disaster Resilience: resources, capacities, learning and action, edited by: Deeming, H., Fordham, M., Kuhlicke, C., Pedoth, L., Schneiderbauer, S., and Shreve, C., Wiley Blackwell, Chichester, West Sussex, United Kingdom, in press, 2018.

Begg, C., Walker, G., and Kuhlicke, C.: Localism and flood risk management in England: The creation of new inequalities?, Environ. Plann. C, 33, 685-702, https://doi.org/10.1068/c12216, 2015.

Begg, C., Ueberham, M., Masson, T., and Kuhlicke, C.: Interactions between citizen responsibilization, flood experience and household resilience: insights from the 2013 flood in Germany, Int. J. Water Resour. D, 33, 1-18, https://doi.org/10.1080/07900627.2016.1200961, 2016.

Berkes, F. and Ross, H.: Community Resilience: Toward an Integrated Approach, Soc. Natur. Resour., 26, 5-20, https://doi.org/10.1080/08941920.2012.736605, 2013.

Berkes, F., Folke, C., and Colding, J. (Eds.): Linking social and ecological systems: Management practices and social mechanisms for building resilience, Cambridge Univ. Press, Cambridge, United Kingdom, 459 pp., 1998.

Birkmann, J., Buckle, P., Jaeger, J., Pelling, M., Setiadi, N., Garschagen, M., Fernando, N., and Kropp, J.: Extreme events and disasters: A window of opportunity for change? Analysis of organizational, institutional and political changes, formal and informal responses after mega-disasters, Nat. Hazards, 55, 637655, https://doi.org/10.1007/s11069-008-9319-2, 2010.

Brand, F. S. and Jax, F. K.: Focusing the Meaning(s) of Resilience: Resilience as a Descriptive Concept and a Boundary Object, Ecol. Soc., 12, 23, 2007. 
Brown, K.: Global environmental change: A social turn for resilience?, Prog. Hum. Geog., 38, 107-117, https://doi.org/10.1177/0309132513498837, 2014.

Carpenter, S., Walker, B., Anderies, J. M., and Abel, N.: From Metaphor to Measurement: Resilience of What to What? Ecosystems, 4, 765-781, https://doi.org/10.1007/s10021-0010045-9, 2001.

Chambers, R. and Conway, G. R.: Sustainable rural livelihoods: Practical concepts for the 21st century, Discussion paper 296, Institute of Development Studies, Brighton, United Kingdom, 42 pp., 1992.

Cote, M. and Nightingale, A. J.: Resilience thinking meets social theory: Situating social change in socio-ecological systems (SES) research, Prog. Hum. Geog., 36, 475-489, https://doi.org/10.1177/0309132511425708, 2012.

Cutter, S. L., Barnes, L., Berry, M., Burton, C., Evans, E., Tate, E., and Webb, J.: A place-based model for understanding community resilience to natural disasters, Global Environ. Chang., 18, 598-606, https://doi.org/10.1016/j.gloenvcha.2008.07.013, 2008.

Cutter, S. L., Ash, K. D., and Emrich, C. T.: The geographies of community disaster resilience, Global Environ. Chang., 29, 6577, https://doi.org/10.1016/j.gloenvcha.2014.08.005, 2014.

Davies, M., Guenther, B., Leavy, J., Mitchell, T., and Tanner, T.: 'Adaptive Social Protection': Synergies for Poverty Reduction, Ids. Bull.-I Dev. Stud., 39, 105-112, https://doi.org/10.1111/j.1759-5436.2008.tb00483.x, 2008.

Davies, M., Bene, C., Arnall, A., Tanner, T., Newsham, A., and Coirolo, C.: Promoting Resilient Livelihoods through Adaptive Social Protection: Lessons from 124 programmes in South Asia, Dev. Policy Rev., 31, 27-58, https://doi.org/10.1111/j.14677679.2013.00600.x, 2013.

Davoudi, S.: Resilience: A Bridging Concept or a Dead End?, Planning Theory \& Practice, 13, 299-333, https://doi.org/10.1080/14649357.2012.677124, 2012.

Deeming, H., Fordham, M., and Swartling, Å. G.: Resilience and Adaptation to Hydrometeorological Hazards, in: Hydrometeorological hazards: Interfacing science and policy, edited by: Quevauviller, P., Wiley Blackwell, Chichester, West Sussex, United Kingdom, 291-316, 2014.

Deeming, H., Davis, B., Fordham, M., and Taylor, S.: River and surface water flooding in Northern England: the civil protectionsocial protection nexus, in: Framing Community Disaster Resilience: resources, capacities, learning and action, edited by: Deeming, H., Fordham, M., Kuhlicke, C., Pedoth, L., Schneiderbauer, S., and Shreve, C., Wiley Blackwell, Chichester, West Sussex, United Kingdom, in press, 2018a.

Deeming, H., Fordham, M., Kuhlicke, C., Pedoth, L., Schneiderbauer, S., and Shreve, C.: Framing Community Disaster Resilience: resources, capacities, learning and action, Wiley Blackwell, Chichester, West Sussex, United Kingdom, in press, $2018 \mathrm{~b}$.

Department for Environment, Food and Rural Affairs: Understanding the risks, empowering communities, building resilience: the national flood and coastal erosion risk management strategy for England: Session: 2010-2012, Unnumbered Act paper, Laid before Parliament 23/05/11, London, 2011.

Doğulu, C., Karanci, A. N., and Ikizer, G.: How do survivors perceive community resilience?: The case of the 2011 earth- quakes in Van, Turkey, Int. J. Disast. Risk. Re., 16, 108-114, https://doi.org/10.1016/j.ijdrr.2016.02.006, 2016.

Dynes, R. R.: Community Social Capital as the Primary Basis for Resilience: Updated Version of Preliminary Paper \#327, Disaster Research Center, University of Delaware, USA, 2005.

Edwards, V. M. and Steins, N. A.: Special issue introduction: The importance of context in common pool resource research, J. Environ. Policy Plann., 1, 195-204, https://doi.org/10.1002/(SICI)1522-7200(199911)1:3<195:AIDJEPP23>3.0.CO;2-U, 1999.

Ensor, J. and Harvey, B.: Social learning and climate change adaptation: Evidence for international development practice, WIREs Clim. Change, 6, 509-522, https://doi.org/10.1002/wcc.348, 2015.

Fainstein, S.: Resilience and Justice: Debates and Developments, Int. J. Urban Regional, 39, 157-167, https://doi.org/10.1111/1468-2427.12186, 2015.

Fekete, A., Hufschmidt, G., and Kruse, S.: Benefits and Challenges of Resilience and Vulnerability for Disaster Risk Management, Int. J. Disaster Risk. Sci., 5, 3-20, https://doi.org/10.1007/s13753-014-0008-3, 2014.

Hayward, B. M.: Rethinking Resilience: Reflections on the Earthquakes in Christchurch, New Zealand, 2010 and 2011, Ecol. Soc., 18, 37, https://doi.org/10.5751/ES-05947-180437, 2013.

Heltberg, R., Siegel, P. B., and Jorgensen, S. L.: Addressing human vulnerability to climate change: Toward a 'no-regrets' approach, Global Environ. Chang., 19, 89-99, https://doi.org/10.1016/j.gloenvcha.2008.11.003, 2009.

Holling, C. S.: Resilience and Stability of Ecological Systems, Annu. Rev. Ecol. Syst., 4, 1-23, https://doi.org/10.1146/annurev.es.04.110173.000245, 1973.

Holling, C. S.: Engineering resileince versus ecological resilience, edited by: Schulze, P. C. and National Academy of Engineering: Engineering within ecological constraints, National Academy Press, Washington, D.C., 31-44, 1996.

Ikizer, G.: Factors related to psychological resilience among survivors of the earthquakes in Van, Turkey, Unpublished doctoral dissertation, Middle East Technical University, Ankara, Turkey, 2014.

Ikizer, G., Karanci, A. N., and Doğulu, C.: Exploring Factors Associated with Psychological Resilience Among Earthquake Survivors from Turkey, Journal of Loss and Trauma, 21, 384-398, https://doi.org/10.1080/15325024.2015.1108794, 2015.

Jacobs, K. and Malpas, J.: The Language of Resilience: Ideas and Action in Contemporary Policy-making, Housing, Theory and Society, 1-16, https://doi.org/10.1080/14036096.2017.1308435, 2017.

Jerneck, A. and Olsson, L.: Adaptation and the poor: development, resilience and transition, Climate Policy, 8, 170-182, https://doi.org/10.3763/cpol.2007.0434, 2008.

Jülich, S.: Towards a local level resilience composite index - Introducing different degrees of indicator quantification, Int. J. Disaster Risk. Sci., 8, 91-99, https://doi.org/10.1007/s13753-0170114-0, 2017.

Jülich, S.: Development of quantitative resilience indicators for measuring resilience at the local level, in: Framing Community Disaster Resilience: resources, capacities, learning and action, edited by: Deeming, H., Fordham, M., Kuhlicke, C., Pedoth, L., 
Schneiderbauer, S., and Shreve, C., Wiley Blackwell, Chichester, West Sussex, United Kingdom, in press, 2018.

Karanci, A. N., Ikizer, G., Doğulu, C., and Özceylan-Aubrecht, D.: Perceptions of Individual and Community Resilience to Earthquakes: A Case Study from Turkey, in: Framing Community Disaster Resilience: resources, capacities, learning and action, edited by: Deeming, H., Fordham, M., Kuhlicke, C., Pedoth, L., Schneiderbauer, S., and Shreve, C., Wiley Blackwell, Chichester, West Sussex, United Kingdom, in press, 2018.

Kates, R. W.: Natural Hazard in Human Ecological Perspective: Hypotheses and Models, Econ. Geogr., 47, 438, https://doi.org/10.2307/142820, 1971.

Kelman, I., Gaillard, J. C., and Mercer, J.: Climate Change's Role in Disaster Risk Reduction's Future: Beyond Vulnerability and Resilience, Int. J. Disaster Risk Sci., 6, 21-27, https://doi.org/10.1007/s13753-015-0038-5, 2015.

Kelman, I., Gaillard, J. C., Lewis, J., and Mercer, J.: Learning from the history of disaster vulnerability and resilience research and practice for climate change, Natural Hazards, 82, 129-143, https://doi.org/10.1007/s11069-016-2294-0, 2016.

Klein, R. J. T., Nicholls, R. J., and Thomalla, F.: Resilience to natural hazards: How useful is this concept?, Environ. Hazards, 5, 35-45, https://doi.org/10.1016/j.hazards.2004.02.001, 2003.

Kuhlicke, C., Callsen, I., and Begg, C.: Reputational risks and participation in flood risk management and the public debate about the 2013 flood in Germany, Environ. Sci. Policy, 55, 318-325, https://doi.org/10.1016/j.envsci.2015.06.011, 2016.

Longstaff, P. H. and Yang, S. U.: Communication management and trust: Their role in building resilience to "surprises" such as natural disasters, pandemic flu, and terrorism, Ecol. Soc., 13, https://doi.org/10.5751/ES-02232-130103, 2008.

MacKinnon, D. and Derickson, K. D.: From resilience to resourcefulness: A critique of resilience policy and activism, Prog. Hum. Geog., 37, 253-270, https://doi.org/10.1177/0309132512454775, 2013.

Matyas, D. and Pelling, M.: Positioning resilience for 2015: the role of resistance, incremental adjustment and transformation in disaster risk management policy, Disasters, 39, 1-18, https://doi.org/10.1111/disa.12107, 2015.

McCarthy, D. D. P., Crandall, D. D., Whitelaw, G. S., General, Z., and Tsuji, L. J. S.: A Critical Systems Approach to Social Learning: Building Adaptive Capacity in Social, Ecological, Epistemological (SEE) Systems, Ecol. Soc., 16, 18, https://doi.org/10.5751/ES-04255-160318, 2011.

McEntire, D. A., Fuller, C., Johnston, C. W., and Weber, R.: A Comparison of Disaster Paradigms: The Search for a Holistic Policy Guide, Public Administration Review, 62, 267-281, https://doi.org/10.1111/1540-6210.00178, 2002.

Moser, C. O. N. and McIlwaine, C.: Violence in a post-conflict context- Urban poor perceptions from Guatemala: Conflict prevention and post-conflict reconstruction series, 1. print, Worldbank, Washington, D.C., USA, 163 pp., 2001.

Mulligan, M., Steele, W., Rickards, L., and Fünfgeld, H.: Keywords in planning: What do we mean by 'community resilience'?, Int. Plan. Stud., 21, 348-361, https://doi.org/10.1080/13563475.2016.1155974, 2016.

Muro, M. and Jeffrey, P.: A critical review of the theory and application of social learning in participatory natural resource management processes, J. Environ. Plann. Man., 51, 325-344, https://doi.org/10.1080/09640560801977190, 2008.

National Acadamies: Disaster Resilience, National Academies Press, Washington, D.C., USA, 2012.

Neal, D.: Reconsidering the Phases of Disaster, International Journal of Mass Emergencies and Disasters, 15, 239-264, 1997.

Nelson, D. R., Adger, W. N., and Brown, K.: Adaptation to Environmental Change: Contributions of a Resilience Framework, Annu. Rev. Environ. Resour., 32, 395419, https://doi.org/10.1146/annurev.energy.32.051807.090348, 2007.

Norris, F. H., Stevens, S. P., Pfefferbaum, B., Wyche, K. F., and Pfefferbaum, R. L.: Community resilience as a metaphor, theory, set of capacities, and strategy for disaster readiness, Am. J. Commun. Psychol., 41, 127-150, https://doi.org/10.1007/s10464007-9156-6, 2008.

Olsson, P., Galaz, V., and Boonstra, W. J.: Sustainability transformations: A resilience perspective, Ecol. Soc., 19, 1, https://doi.org/10.5751/ES-06799-190401, 2014.

Orach, K. and Schlüter, M.: Uncovering the political dimension of social-ecological systems: Contributions from policy process frameworks, Global Environ. Chang., 40, 13-25, https://doi.org/10.1016/j.gloenvcha.2016.06.002, 2016.

Ostrom, E.: Understanding institutional diversity, Princeton University Press, Princeton, USA, 2005.

Partzsch, L.: 'Power with' and 'power to' in environmental politics and the transition to sustainability, Environ. Pol., 26, 193-211, https://doi.org/10.1080/09644016.2016.1256961, 2017.

Patel, S. S., Rogers, M. B., Amlôt, R., and Rubin, G. J.: What Do We Mean by 'Community Resilience'? A Systematic Literature Review of How It Is Defined in the Literature, PLOS Currents Disasters, http://currents.plos.org/disasters/article/ what-do-we-mean-by-community-resilience-a-systematic-literature-review2017.

Paton, D. F.: Community Resilience: Integrating Hazard Management and Community Engagement, in: Proceedings of the International Conference on Engaging Communities, edited by: United Nations \& Queensland State Government, International Conference on Engaging Communities, Brisbane, Queensland, Australia, 14-17 August 2005, 2005.

Pedoth, L., Taylor, R., Kofler, C., Stawinoga, A. E., Matin, N., Forrester, J., and Schneiderbauer, S.: The role of risk perception and community networks in preparing for and responding to landslides: a Dolomite case study, in: Framing Community Disaster Resilience: resources, capacities, learning and action, edited by: Deeming, H., Fordham, M., Kuhlicke, C., Pedoth, L., Schneiderbauer, S., and Shreve, C., Wiley Blackwell, Chichester, West Sussex, United Kingdom, in press, 2018.

Pelling, M.: Adaptation to climate change: From resilience to transformation, Routledge, London, United Kingdom, 203 pp., 2011.

Reed, M. S., Evely, A. C., Cundill, G., Fazey, I., Glass, J., Laing, A., Newig, J., Parrish, B., Prell, C., Raymond, C., and Stringer, L. C.: What is Social Learning?, Ecol. Soc., 15, https://doi.org/10.5751/ES-03564-1504r01, 2010.

Ross, H. and Berkes, F.: Research Approaches for Understanding, Enhancing, and Monitoring Community Resilience, Soc. Natur. Resour., 27, 787-804, https://doi.org/10.1080/08941920.2014.905668, 2014. 
Schneiderbauer, S. and Ehrlich, D.: Social levels and hazard (in)dependence in determining vulnerability, in: Measuring vulnerability to natural hazards: Towards disaster resilient societies, edited by: Birkmann, J., United Nations Univ. Press, Tokyo, Japan, 78-102, 2006.

Scoones, I.: Sustainable Rural Livelihoods. A Framework for Analysis, IDS Working Paper, 72, 1998.

Shaw, K.: The Rise of the Resilient Local Authority?, Local Gov. Stud., 38, 281-300, https://doi.org/10.1080/03003930.2011.642869, 2012.

Sherrieb, K., Norris, F. H., and Galea, S.: Measuring Capacities for Community Resilience, Soc. Indic Res., 99, 227-247, https://doi.org/10.1007/s11205-010-9576-9, 2010.

Sjöstedt, M.: Resilience revisited: taking institutional theory seriously, Ecol. Soc., 20, https://doi.org/10.5751/ES-08034-200423, 2015.

Smith, A. and Stirling, A.: The Politics of Social-ecological Resilience and Sustainable Socio-technical Transitions, Ecol. Soc., $15,11,2010$.

Strunz, S.: Is conceptual vagueness an asset?: Arguments from philosophy of science applied to the concept of resilience, Ecol. Econ., 76, 112-118, https://doi.org/10.1016/j.ecolecon.2012.02.012, 2012.

Sudmeier-Rieux, K.: Resilience - an emerging paradigm of danger or of hope?, Disaster Prevention and Management: An International Journal, 23, 67-80, https://doi.org/10.1108/DPM-122012-0143, 2014.

Szerszynski, B.: Risk and Trust: The Performative Dimension, Environ. Value, 8, 239-252, https://doi.org/10.3197/096327199129341815, 1999.
Taylor, R., Forrester, J., Pedoth, L., and Matin, N.: Methods for Integrative Research on Community Resilience to Multiple Hazards, with Examples from Italy and England, Proc. Econ. Financ., 18, 255-262, https://doi.org/10.1016/S2212-5671(14)00938-1, 2014.

Tobin, G.: Sustainability and community resilience: The holy grail of hazards planning?, Global Environ. Chang., Part B: Environmental Hazards, 1, 13-25, https://doi.org/10.1016/S14642867(99)00002-9, 1999.

United Nations Office for Disaster Risk Reduction: Sendai Framework for Disaster Risk Reduction 2015-2030, United Nations International Strategy for Disaster Reduction, 2015.

United Nations Office for Disaster Risk Reduction: Hyogo Framework for Action 2005-2015: Building the Resilience of Nations and Communities to Disasters, United Nations International Strategy for Disaster Reduction, 2007.

Walker, B. and Westley, F.: Perspectives on resilience to disasters across sectors and cultures, Ecol. Soc., 16, https://doi.org/10.5751/ES-04070-160204, 2011.

Weichselgartner, J. and Kelman, I.: Geographies of resilience: Challenges and opportunities of a descriptive concept, Prog. Hum. Geog., 39, 249-267, https://doi.org/10.1177/0309132513518834, 2015.

Whaley, L. and Weatherhead, E. K.: An Integrated Approach to Analyzing (Adaptive) Comanagement Using the "Politicized" IAD Framework, Ecol. Soc., 19, 10, https://doi.org/10.5751/ES06177-190110, 2014.

Wilson, G. A.: Community resilience: Path dependency, lock-in effects and transitional ruptures, J. Environ. Plann. Man., 57, 1-26, https://doi.org/10.1080/09640568.2012.741519, 2013. 